\title{
Experimental Investigation of Cutting Parameters Effects on the Surface Roughness and Tools Wear during the Drilling of Fiber Reinforced Composite Materials
}

\author{
IRSHAD ULLAH*, MUHAMMAD WASIF*, MUHAMMAD TUFAIL**, MUHAMMAD ADNAN KHAN*, \\ AND SYED AMIR IQBAL*
}

RECEIVED ON 18.01.2018 ACCEPTED ON 17.08.2018

\begin{abstract}
Optimization of the drilling parameters of the composite material is the key objective of this research, enhancing the surface roughness and minimizing the tool wear. In contrary to the other research, optimizing the machining parameters for a specific composite material for the mass productions, machining parameters are optimized for GFRP (Glass Fiber Reinforced Polymer), CFRP (Carbon Fiber Reinforced Polymer) and KFRP (Kevlar Fiber Reinforced Polymer) for the job shop production. In this research, the machining parameters are optimized for the enhanced surface roughness and minimum tool wear by varying the three types of composite material and three levels of the cutting speed. Nine experiments were performed, which were repeated twice in random manner to eliminate the biasness of the results. In these experiments, PVD (Physical Vapor Deposition) coated carbide inserts are used with the same geometry. Seventeen holes were machined in a single experiment, which surface roughness is measured by cutting the composite plate from middle of the hole and using the Countermatic surface roughness meter at different locations. Average surface roughness is determining for each set of varying parameters and plotted to observe the set of parameters for the minimum surface roughness. It has been observed that the minimum surface roughness are observed at; 1500rpm in GFRP, 2000rpm in CFRP and at 2500rpm in KFRP. Finally, the wear patterns are also observed on the drill inserts using SEM (Scanning Electron Microscope) and it has been found that no prominent wear has been observed in the drill inserts, whereas, prominent depletion of coating are found at the higher cutting speed.
\end{abstract}

Key Words: Composite Materials, Drilling, Optimization, Surface Roughness, Tool Wear.

\section{INTRODUCTION}

omposite materials are the combination of two or more materials, combined to provide better mechanical properties than the individual ones. In the past, this technology was found in making composite bricks from straws and clay. The force behind the increased application of composites is the ability to tailor the materials to the requirements and the superior properties which are gained after the combination of

Authors E-Mail: (irshad ullah@hotmail.com, wasif@neduet.edu.pk, deancpe@neduet.edu.pk, nizami992@yahoo.com, samir@neduet.edu.pk) * Department of Industrial and Manufacturing Engineering, NED University of Engineering \& Technology, Karachi, Pakistan.

** Department of Chemical Engineering, NED University of Engineering and Technology, Karachi, Pakistan.

This is an open access article published by Mehran University Research Journal of Engineering and Technology, Jamshoro under the CC by 4.0 International License. 
two more materials. High specific stiffness and strength along with the greater dimensional stability under a wide range of atmospheric conditions including temperature which is essential in exotic applications, such as; aircraft, high speed cars, wind turbines, satellite bodies, equipment casing in rockets, high pressure fuel tanks, bullet proof armors, helmets etc. Composite materials have high strength to weight ratio as compared to conventional materials, hence used a lot in aerospace industry. Moreover, sensors can also be embedded inside the body to monitor the stresses on the critical areas of the aircraft and other applications [1]. Composite material is usually made of matrix and reinforcement materials that are mixed in certain proportions depending on the requirement. Two or more constituent materials have their own properties which exhibit desired properties when combined together which is the most important aspect of composite due to its tailor ability. Reinforcements such as fibers, particles and whiskers have great strength and stiffness. When these materials are combined with weaker matrix (usually known as matric material), a composite with lesser properties than the actual fibers are however, produced but the overall composite properties in general will have considerable difference to that of conventional matrix materials. The most common type of matrix materials used in the composite materials are; epoxy, polyester, and phenol formaldehyde resins, whereas, glass, carbon, Kevlar or organic long fibers are majorly used to achieve the favorable mechanical and especially thermal properties [2].

Hole and some feature in composite based parts are usually performed after the curing of composite material, since it is difficult to embed some minute and small feature into the cavity, which may also result in developing critical stress in the parts. Due to heterogeneity of composite materials, the machining of composites is the prime concern. Drilling is one of the main machining operations probably most widely applied to polymeric matrix composites owing to the need to assemble components, produced mainly as laminates, through riveting and bolting. For example, 100,000 holes are required in a small engine aircraft and millions of holes are necessary for a larger one [3]. Composite laminates are reported as the hard-to-machine materials, usually results in very low machining efficiency with lower tool life and surface finish. To address this issue, several investigations were performed by researchers to improve the tool life, surface finish and operating cost of drilling on the composite material [4-5].

A study on PMCRLF (Polymer Matrix Composites Reinforced by Long Fibers) were performed which are an important class of materials in advanced structural applications due to their lightweight, high modulus and high specific strength. It was observed that due to the anisotropic and heterogeneous nature, composite surfaces often contain damage such as delamination, cracks and fiber dislodgements [6]. Zhang et. al. [7] in their research on the same material reports the significant investigations to understand the mechanics of cutting, the effect of fiber orientation and PMCRLF fabrication conditions on the quality of machined surfaces using cutting, drilling and grinding. Hisahiro Inoue et al investigated by drilling large number of holes in glass/epoxy-resin GFRP with high speed machining. They observed that the quality of holes are improved for the large number of holes with the high speed machining. Tool life of small diameters drills were also reported to be depended upon the fiber width [8]. In another study, AFRP (Aramid Fibre Reinforced 
Polymer) was drilled with different machining parameters to study the effect of these parameters on the tool life. Conclusion of the research was vague and defines that the larger rake angle with constant edge radii reduces the cutting force. It does not show the increased tool life and productivity of the process [9]. In a research, a pre-hole drilling process is performed chisel length of drill is also varied to observe the drill delamination [10]. In another research, drilling on GFRP's, manufactured with hand lay-up process, was performed to develop a relationship between the cutting velocity and feed rate under the constant thrust force, cutting pressure and surface roughness [11]. In a comprehensive review, machining parameters and influence of these on the thrust force and torque are studied. In addition, quality of the holes and delamination damage are also discussed [12]. A group of researchers combined the stack of titanium, CFRPs and aluminum to study the quality of holes produced using different machining parameters. They concluded that the delamination was least in the CRFP as compared to the stand-alone machining [13]. Numerical and experimental researches were performed, combining the stacks of composite and other metal to study the effect of thrust force and tool life; the machining parameters were optimized to increase the quality of hole and the long life of the tool [14-17]. Similar research was performed using the coated and uncoated tool to study the same effects, and the obvious result was found that is the coated drills are better than the uncoated ones [18]. Another interesting work has been performed by a group of researchers performing gun-drilling process on a thick composite material plate. In this research, critical zone in the plate thickness was found which cause the delamination in the drill tool [19]. Another research on thick epoxy based composite was performed, and it was analyzed that the cutting forces are depend upon the fiber orientation and three flute and four-facet WC (Tungsten Carbide) twist drills are suitable for pultruded and LCM (Liquid Composite Moulding) composites [20].

Most of the research discussed above was focused on optimization of the cutting parameters and tools design based on the specific combination of matrix material and fiber [4-20]. Since the above-mentioned researches were performed for the mass production systems, hence it may justify the specific composite material and expensive drill tool design. Recommended tool material for machining of composites is PCD (Poly Crystalline Diamond) but being extremely expensive this tooling leads to high cost of the finished product. Moreover, in the areas where job shop or process-oriented production is mostly adopted, it is high need of the industry to acquire the generic drill tooling, which should be productive for most of the common types of composite materials, rather than the specific tooling. Hence, on demand of research based institution, producing different composite products, such as, wind turbine, motor casings for rockets, helmets etc., a research is carried out to select the appropriate machining parameters for different types of composite material, producing the better surface finish and longer tool life. Therefore, a focused research is conducted for the drilling of glass, carbon and Kevlar reinforced epoxy composite using the PVD coated cemented carbide tool, to determine the specific machining parameters for all the three types of composite materials with constant fiber orientations and same types of matrix and reinforcement composition. Although the surface finish in the composite material is not critical but may reduce the grinding and other finishing processes, resulting in the lower cost of manufacturing. The limitation of this research is; the effect 
of vibrations on the surface roughness has been neglected which is very minor since the machine, spindle and tool are designed for the machining of aerospace grade metals. Hence the vibration in the system due to epoxy based composites are minors.

\section{EXPERIMENTAL SETUP}

As mentioned earlier, the core objective of the research is to determine the optimal set of drilling parameters for the recommended surface finish and the least tool wear and damage. For this purpose, an experimental setup has been designed, consisting of; PVD coated cemented carbide tool inserts with the appropriate tool holders, three different types of composite materials and $\mathrm{CNC}$ (Computer Numeric Control) milling machine for the drilling. To perform the analysis, the sequence of the study has been described by:

(1) Acquiring drill tool and its accessories

(2) Preparation of composite work-piece

(3) Designing experiments

(4) Performing drilling experiments on composite work-piece

Measurement of surface roughness using the Surface roughness meter

Observing the enhanced image of the tools wear using the SEM.

The selection of tool grade and geometry greatly affects the choice of cutting speed and feed rate to be employed when drilling fiber-reinforced polymeric laminates. However, in contrast to metals, drills used to machine polymeric composites can simultaneously withstand high cutting speeds and feed rates. Additionally, the choice of drill diameter depends on the design of the component to be machined rather than on the optimal cutting conditions and determines, together with cutting speed and feed rate, the metal removal rate and, consequently, drilling power. Nevertheless, a number of reports such as [10-11] point out the importance of pre-drilling in order to reduce damage in composite materials.

Typical values for the cutting speed generally ranges from $20-60 \mathrm{~m} / \mathrm{min}$ and $0.3 \mathrm{~mm} / \mathrm{rev}$ is the maximum value for feed rate usually found in the published literature for the drilling of fiber-reinforced composites with high-speed steel and tungsten carbide drills [12]. These conservative values may be explained by the following reason: in the case of cutting speed, higher values may cause the softening of the matrix and clogging of this phase on the cutting tool.

For the experimental purpose, a benchmark tooling of $13.5 \mathrm{~mm}$ diameter is selected for which indexible type drilling inserts (ZCMT050203) of PVD coated carbide is used, to perform the drilling on FRP composite materials. Using the designation of insert (ZCMT050203), it is to be interpreted that the diamond shape tool with $80^{\circ}$ inscribed angle, $7^{\circ}$ clearance angle, edge length of $5 \mathrm{~mm}$, thickness $2 \mathrm{~mm}$ and corner radius of $3 \mathrm{~mm}$ is used. For the selected drilling insert, tool holder S20 - DRZ135405-05 of KYOCERA is selected having the drill diameter of $13.5 \mathrm{~mm}$, tool and flank lengths of 108 and $65 \mathrm{~mm}$ respectively and providing the four cutting edges with the indexible inserts. It is also important to mention that the PVD coated carbide grades are based on ceramic thin film technology and are good for drilling, milling, threading, grooving, and stainless-steel cutting. Very tough carbide substrate and innovative coating technology promote excellent wear resistance and strong coating adhesion for long tool life and stable machining [20]. 
Initially GFRP, CFRP and KFRP specimen are prepared using the vacuum infusion technique. In this research, the weaved fabric of fibers is used, which waived in the 0$90^{\circ} \mathrm{C}$ pattern. These specimens were cured in the autoclave at 6 bar and $130^{\circ} \mathrm{C}$. Six samples were prepared with the dimensions of 1000x120x8mm having fiber to resin volume fraction of $65: 35$. The thickness of the composite workpiece is chosen based on the requirement of the customer, which is maximum thickness cut by customer during the machining of the parts.

An experimental setup has been designed to perform the drilling operations on the composite work-piece. A CNC milling machine of FEELER is used for the purpose of drilling operations having the maximum feed rate of $3000 \mathrm{~mm} / \mathrm{min}$, spindle speed of $6000 \mathrm{rpm}$ having 3 -axis setup (Fig. 1). A total of 18 experiments are designed (three for each fiber material, repeated twice) and during each experiment 17 holes are drilled for each material. For conducting each experiment, fresh drilling inserts are used and after machining each insert is marked with specific color coding for proper traceability. Parameters shown in Table 1 are selected to study the influence of these on surface finish and tool wear of the composite material. The spindle speed is selected based on the recommended values of the tool catalog for the machining of composite material.

It is important to mention that several parameters are fixed to observe the effect of the varying parameters. The parameters which are kept constant include; material of the drilling tool, parameters of the drill insert, feed rate as set to be $0.02 \mathrm{~mm} / \mathrm{rev}$., polymeric matrix material, diameter of hole as set to be $13.5 \mathrm{~mm}$, coating of the tool insert is TiAlN fine surface coating (PVD) [21].

To repeat the experiment twice, each of the three-material work-pieces were duplicated and hence six work-pieces of three types of composite materials were prepared. Minitab software is used to design the experiments randomly to reduce the biasness in the results. In each of the work-piece, three experiments were performed with the varying spindle speed. Feed rates and the cutting velocities were calculated and set as the machining

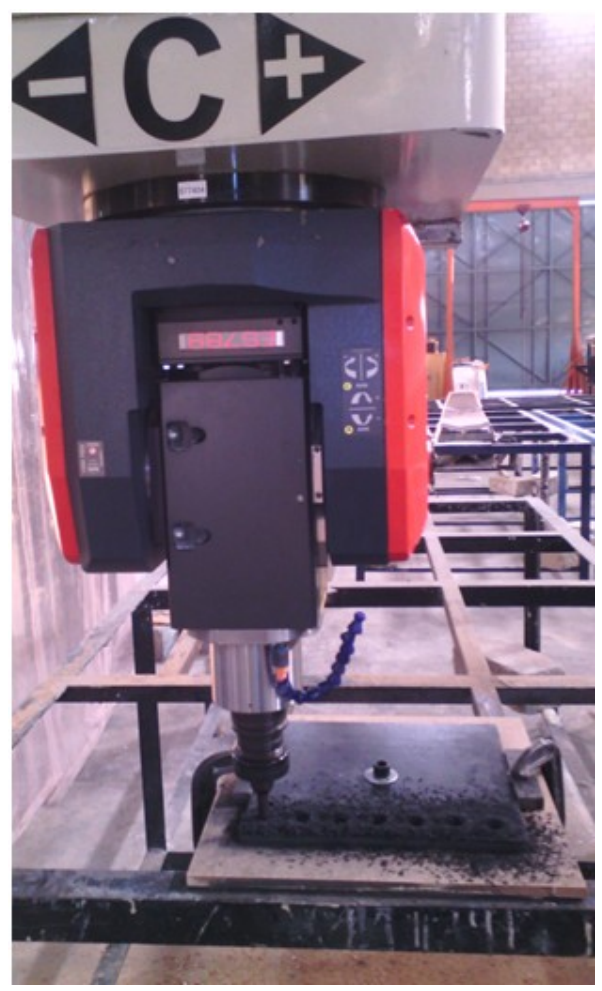

FIG. 1. DRILLING OF HOLES IN THE CFRP COMPOSITE MATERIAL

TABLE 1. VARYING PARAMETERS FOR THE EXPERIMENTS

\begin{tabular}{|c|c|c|c|c|}
\hline Parameters & Level & 1 & 2 & 3 \\
\hline Workpiece Material & 3 & $\begin{array}{c}\text { Glass Fiber Reinforced } \\
\text { Polymer }\end{array}$ & $\begin{array}{c}\text { Carbon Fiber Reinforced } \\
\text { Polymer }\end{array}$ & $\begin{array}{c}\text { Kevlar Fiber Reinforced } \\
\text { Polymer }\end{array}$ \\
\hline Spindle Speed (rpm) & 3 & 1500 & 2000 & 2500 \\
\hline
\end{tabular}

Mehran University Research Journal of Engineering \& Technology, Volume 38, No. 3, July, 2019 [p-ISSN: 0254-7821, e-ISSN: 2413-7219] 
parameters based on the varying spindle speeds and the constant feed rate. During each experiment, 17 holes were machined in the composite material without any delay to observe the effect of machining on the delamination of the drill tool. Work-pieces and drill inserts were marked with the color for the traceability and analysis of wear as shown in Table 2.

To measure the effect of the vibration on the drilled samples, diameter of each hole is measured using the digital Vernier caliper with the least count of $0.001 \mathrm{~mm}$, average of holes has been taken, hence for all three spindle speeds, three hole sizes in each material has been determined. Using the standards of ISO 286-1 (2010), ISO 286-2 (2010) and ANSI B4.2 (1978) hole tolerance of H11 (ANSI B4.2) has be selected which is equivalent to I11 (ISO 286-1 and ISO 286-2). This class of hole tolerance is selected as per the recommendation of manufacturer of tool in their catalogue [21]. The Maximum upper limit of hole tolerance for the drill hole of diameter $13.5 \mathrm{~mm}$ is $0.11 \mathrm{~mm}$. That is allowable hole size is $13.61 \mathrm{~mm}$ maximum. Average hole diameter in GFRP, CFRP and KFRP are measured as $13.582,13.566$, and $13.634 \mathrm{~mm}$ respectively. The drilling process during the machining of all holes were observed carefully and it has been observed that the average hole diameter in KFRP is higher (higher than the allowable which can be controlled by selecting smaller drill tool) due to the wrapping of fibers with the drill tool rather than the vibration, this wrapping effect also exists in case of GFRP and KFRP, since the same type of epoxy has been used in all three types of composite materials. Based on this measurement, it is determined that the machining vibration has effect on the drilled holed, but in composite materials, the wrapping of fibers around the tool cause the enlargement in hole and hence it is difficult to measure the impact of vibration on the surface finish of the composite material.

After drilling the holes in the composite materials, the work-pieces were cut in half so that half of the drilled hole can be seen as the front view is shown in Fig. 2 .

Wilson Wolpert's Conturo Matic T2 Surface roughness meter is shown in Fig. 3 is used for measuring roughness of the drilled hole in the work piece along the hole axial direction. The stylus is moved and the surface roughness values are observed at both halves of the work piece and at various locations. Roughness values are observed in millimeters. Sample figure obtained from the ConturoMatic is shown in Fig. 4.

TABLE 2. FEED RATES AND CUTTING SPEED DESIGNATED FOR THE COMPOSITE MATERIALS

\begin{tabular}{|c|c|c|c|c|c|c|c|}
\hline No. & $\begin{array}{c}\text { Spindle Speed } \\
(\mathrm{rpm})\end{array}$ & $\begin{array}{c}\text { Feed } \\
(\mathrm{mm} / \mathrm{rev} / \mathrm{tooth})\end{array}$ & $\begin{array}{c}\text { Feed Rate } \\
(\mathrm{mm} / \mathrm{min})\end{array}$ & $\begin{array}{c}\text { Cutting Speed } \\
(\mathrm{m} / \mathrm{min})\end{array}$ & Fiber Type & Color Marking & $\begin{array}{c}\text { Experiment } \\
\text { Designation }\end{array}$ \\
\hline 1. & 1500 & 0.02 & 60 & 63.6 & GFRP & Green & G1, G2 \\
\hline 2. & 2000 & 0.02 & 80 & 84.8 & GFRP & Red & R1, R2 \\
\hline 3. & 2500 & 0.02 & 100 & 106 & GFRP & Blue & B1, B2 \\
\hline 4. & 1500 & 0.02 & 60 & 63.6 & CFRP & Green & G3, G4 \\
\hline 5. & 2000 & 0.02 & 80 & 84.8 & CFRP & Red & R3, R4 \\
\hline 6. & 2500 & 0.02 & 100 & 106 & CFRP & Blue & B3, B4 \\
\hline 7. & 1500 & 0.02 & 60 & 63.6 & KFRP & Green & G5, G6 \\
\hline 8. & 2000 & 0.02 & 80 & 84.8 & KFRP & Red & R5, R6 \\
\hline 9. & 2500 & 0.02 & 100 & 106 & KFRP & Blue & B5, B6 \\
\hline
\end{tabular}




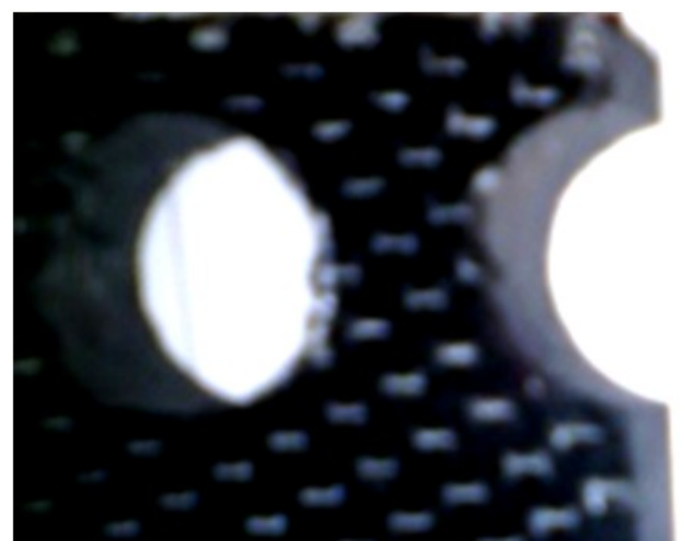

FIG. 2. HALF HOLE IS CUT TO MEASURE THE ROUGHNESS OF THE DRILLED HOLE IN CFRP

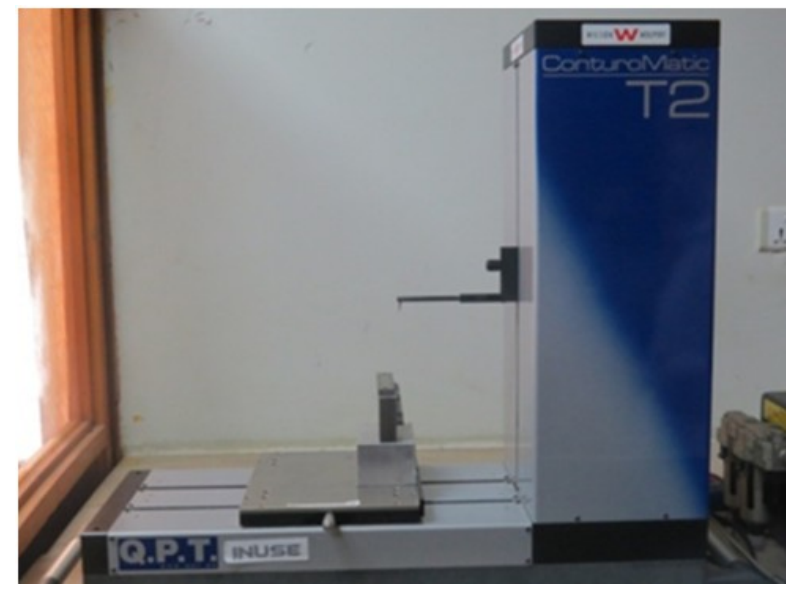

FIG. 3. WILSON WOLPERT'S CONTUROMATIC T2 SURFACE ROUGHNESS METER

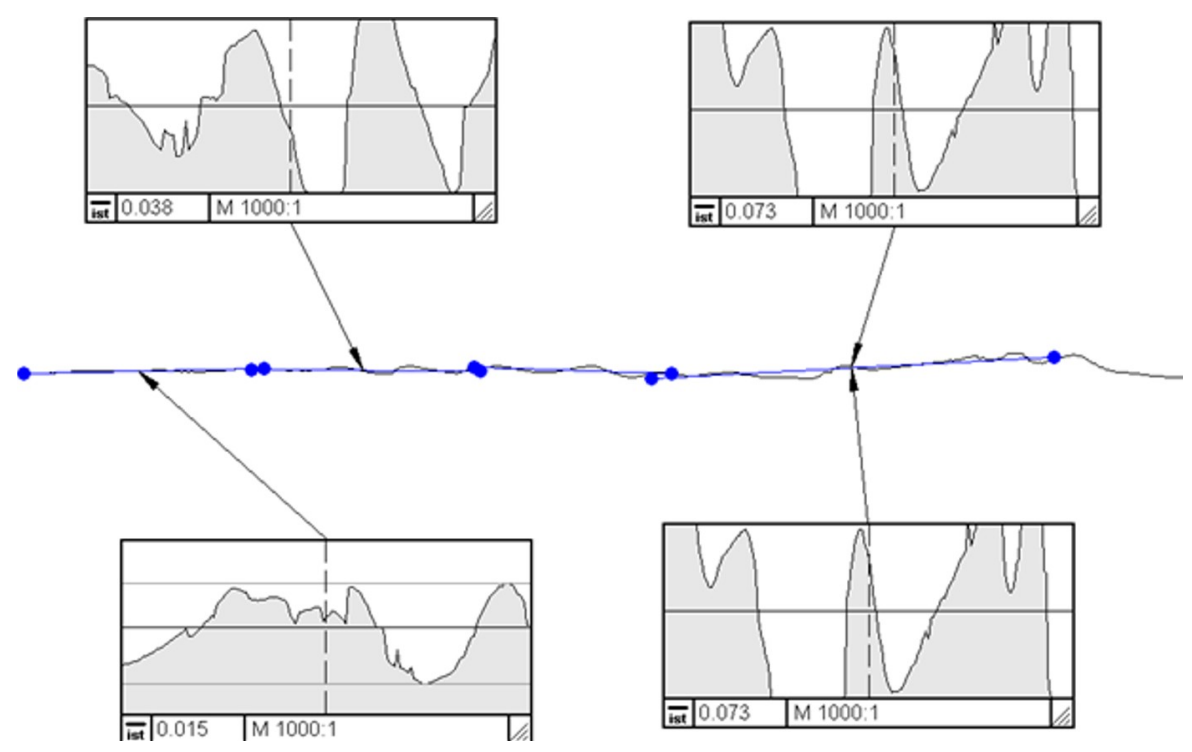

FIG. 4. SURFACE ROUGHNESS OF DRILLED HOLE IN GFRP (AT 1500RPM)
The microscope provides materials characterization, chemical analysis, fractography and failure analysis of materials. Electron microscopy is a technique used for looking into the materials at high magnification. It provides vital information, which affects the metallurgical, mechanical, physical and chemical properties of the finished products. SEM (Scanning Electron Microscope) is used for the analysis of tool wear of drilling inserts after machining at parameters. Inserts are mounted and analyzed after magnification of around 50, 100 and 200x and the images are then compared with one another. The SEM is shown in Fig. 5.

\section{RESULTS AND ANALYSIS}

Surface roughness values are measured and the data is analyzed. Roughness value for each material is plotted against spindle speed for drilling the samples in order to correlate these two parameters. It also leads to the result about optimal value of spindle speed that will bring about the better surface finish of the drilled work pieces. Table 3 represents the machining parameter and the average surface roughness is calculated, comparing with each other. 
For each fiber materials following figures are plotted, showing the effect of spindle speed (on $\mathrm{x}$-axis) on surface roughness value (on y-axis). In drilling GFRP samples, at lower spindle speed of the three values, i.e. at 1500 RPM, better surface finish is achieved while for CFRP samples, as spindle speed is 2000 RPM (between lower and higher value), surface roughness value decreased, better surface is achieved. In drilling KFRP samples, minimum surface roughness value is achieved at 2500 RPM (highest spindle speed). Comparing the results of all the three FRP samples after performing drilling operation, dependence of spindle speed was observed on the surface roughness value for all three types of the composite material (Fig. 6). From Fig. 6, it can also be observed that the highest surface roughness after the machining was observed in the KFRP, which is mainly due to the thin and soft nature of the Kevlar fibers, whereas, the least surface roughness is measured in the GFRP, due to the brittleness of glass fiber.

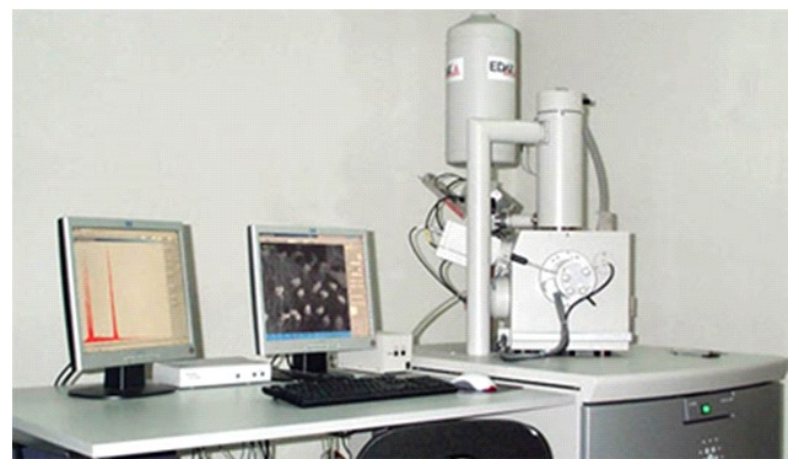

FIG. 5. SCANNING ELECTRON MICROSCOPE
Figs. 7-14 presents the comparison among the different images of drilling inserts obtained after the machining of the holes, whereas, a fresh drill insert is shown in Fig. 7 to compare the image with the used inserts.

While drilling the GFRP at 1500 and $2000 \mathrm{rpm}$, no prominent wear in the insert or its coating was observed, while, drilling the GFRP at $2500 \mathrm{rpm}$, sticking of glass fiber particles on the drill inserts were observed which can also lead to the built up edge at the high feed rates. These observations are shown in Fig. 8. Although the roughness in the hole while machining GFRP at 1500 and 2000rpm were higher, hence the observations shows that there is no relation between the roughness and the tool wear during the drilling of CFRP.

The conditions of drill inserts used for machining the CFRPs were investigated. It was observed that the insert which drilled the CFRP with the 1500rpm had their PVD coating removed after the machining. It shows that the carbon fiber composite material at this spindle speed generates high temperature at the cutting edges which caused the depletion of coating from the edges and it's nearby as shown in Fig 9. It can also be observed that despite of the high temperature, the composite material sticks with the flank of the tool rather than the face of the tool causing the lower surface roughness on the hole.

TABLE 3. SURFACE ROUGHNESS OBTAINED ON EACH WORK-PIECE

\begin{tabular}{|c|c|c|c|c|c|c|c|}
\hline $\begin{array}{l}\text { Experiment } \\
\text { Designation }\end{array}$ & $\begin{array}{l}\text { Spindle Speed } \\
\text { (rpm) }\end{array}$ & $\begin{array}{c}\text { Feed } \\
\text { (mm/rev/tooth) }\end{array}$ & $\begin{array}{c}\text { Feed Rate } \\
(\mathrm{mm} / \mathrm{min})\end{array}$ & $\begin{array}{l}\text { Cutting Speed } \\
(\mathrm{m} / \mathrm{min})\end{array}$ & Fiber Type & $\begin{array}{l}\text { Avg. Surface } \\
\text { Roughness (mm) }\end{array}$ & Remarks \\
\hline $\mathrm{G} 1, \mathrm{G} 2$ & 1500 & 0.02 & 60 & 63.6 & GFRP & 0.042 & \multirow{3}{*}{$\begin{array}{l}\text { Minimum for } \\
\text { GFRP }\end{array}$} \\
\hline $\mathrm{R} 1, \mathrm{R} 2$ & 2000 & 0.02 & 80 & 84.8 & $\overline{\text { GFRP }}$ & 0.065 & \\
\hline B1, B2 & 2500 & 0.02 & 100 & 106.0 & GFRP & 0.049 & \\
\hline G3, G4 & 1500 & 0.02 & 60 & 63.6 & CFRP & 0.040 & \multirow{3}{*}{$\begin{array}{l}\text { Minimum for } \\
\text { CFRP }\end{array}$} \\
\hline R3, R4 & 2000 & 0.02 & 80 & 84.8 & CFRP & 0.020 & \\
\hline B3, B4 & 2500 & 0.02 & 100 & 106.0 & CFRP & 0.026 & \\
\hline G5, G6 & 1500 & 0.02 & 60 & 63.6 & KFRP & 0.068 & \multirow{3}{*}{$\begin{array}{l}\text { Minimum for } \\
\text { KFRP }\end{array}$} \\
\hline R5, R6 & 2000 & 0.02 & 80 & 84.8 & KFRP & 0.076 & \\
\hline B5, B6 & 2500 & 0.02 & 100 & 106.0 & KFRP & 0.054 & \\
\hline
\end{tabular}

Mehran University Research Journal of Engineering \& Technology, Volume 38, No. 3, July, 2019 [p-ISSN: 0254-7821, e-ISSN: 2413-7219] 
It can be observed from the images that the drill inserts which machined the CFRP at 2000rpm had their coating depleted but also the built-up edges are formed at the face of the tool causing the lowest surface roughness at this spindle speed in the CRFP work-piece (Figs. 10-11). While machining CFRP at 2500rpm, it has been observed that the built-up edges were not formed but the PVD coating was depleted highly at the cutting edges, whereas, flank was severally depleted by the rubbing action against the CFRP at high cutting speed. The CFRP material also stuck with the relief surface while machining with 2000rpm.

In Kevlar, it was observed that the cutting edge and face was not affected by the drilling process with having spindle speed of 1500 and 2000 (Figs. 12-13), however, the flank coating was depleted due to the rubbing action (Fig. 12). Although, the sever depletion of PVD coating was observed while machining the KFRP at 2500rpm (

Fig. 14). It can be seen from the figure that the face and flank are naked from the PVD coating but the composite material was not at all sticken with any of the face.

Based on the performed experiments and wear pattern, it has been observed that the PVD coated carbide inserts are suitable for drilling any of these three types of the composite materials. Drilling parameters should however, be decided for the minimum surface roughness obtained in the experiments. It can also be concluded that it is difficult to draw the relationship between the wear of the tool and the surface roughness in the drilling process of the composite material due to the sticking of composite material on the face and the flank. Although, the PVD coating of the tools were depleted at the higher cutting speed but it can be concluded that during the drilling of composite material, heat decapitation is easier at the lower cutting speed causing the composite material not to stick on the face and flank and also not depleting the coating on the inserts.

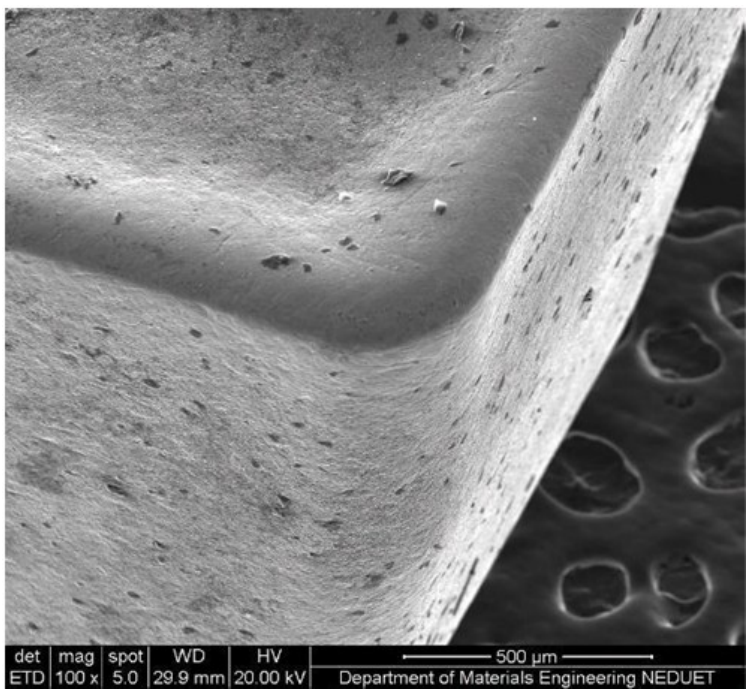

FIG. 7. SEM IMAGE OF FRESH DRILLING INSERT

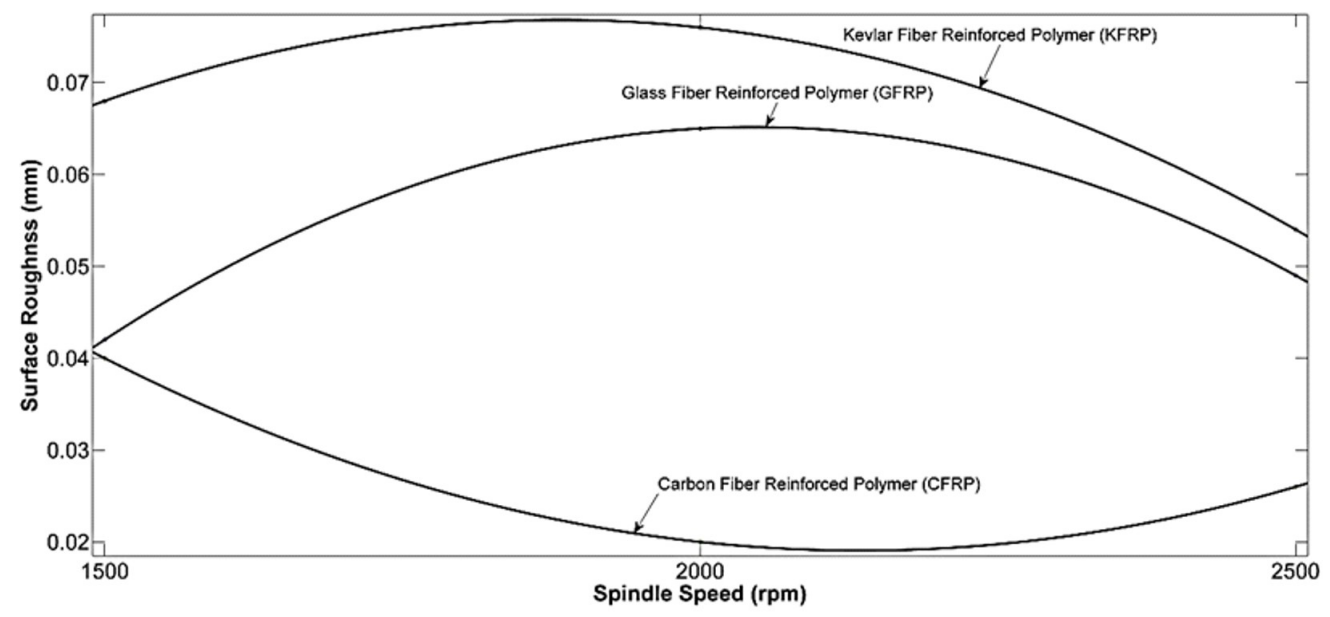

FIG. 6. SURFACE ROUGHNESS MEASURED ON THE THREE COMPOSITE WORK-PIECES

Mehran University Research Journal of Engineering \& Technology, Volume 38, No. 3, July, 2019 [p-ISSN: 0254-7821, e-ISSN: 2413-7219] 

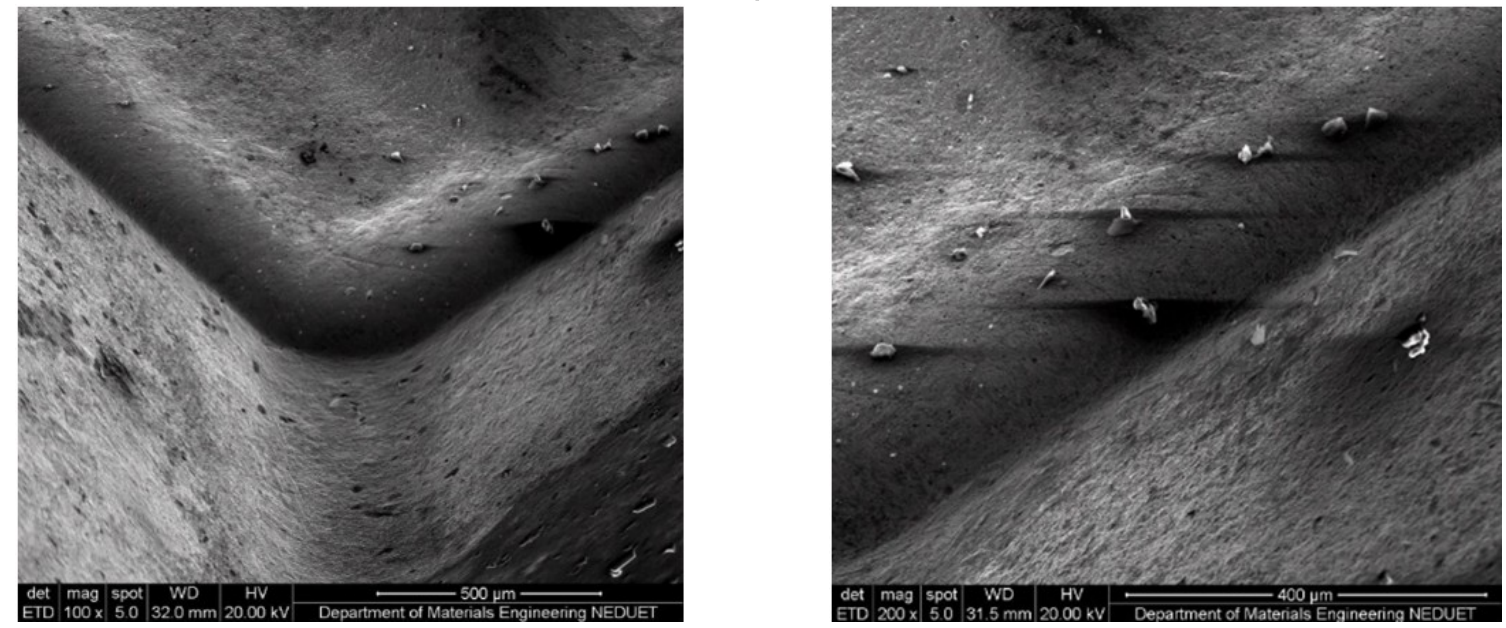

FIG. 8. SEM IMAGES OF DRILLING INSERTS AFTER THE MACHINING OF GFRP AT 2500RPM
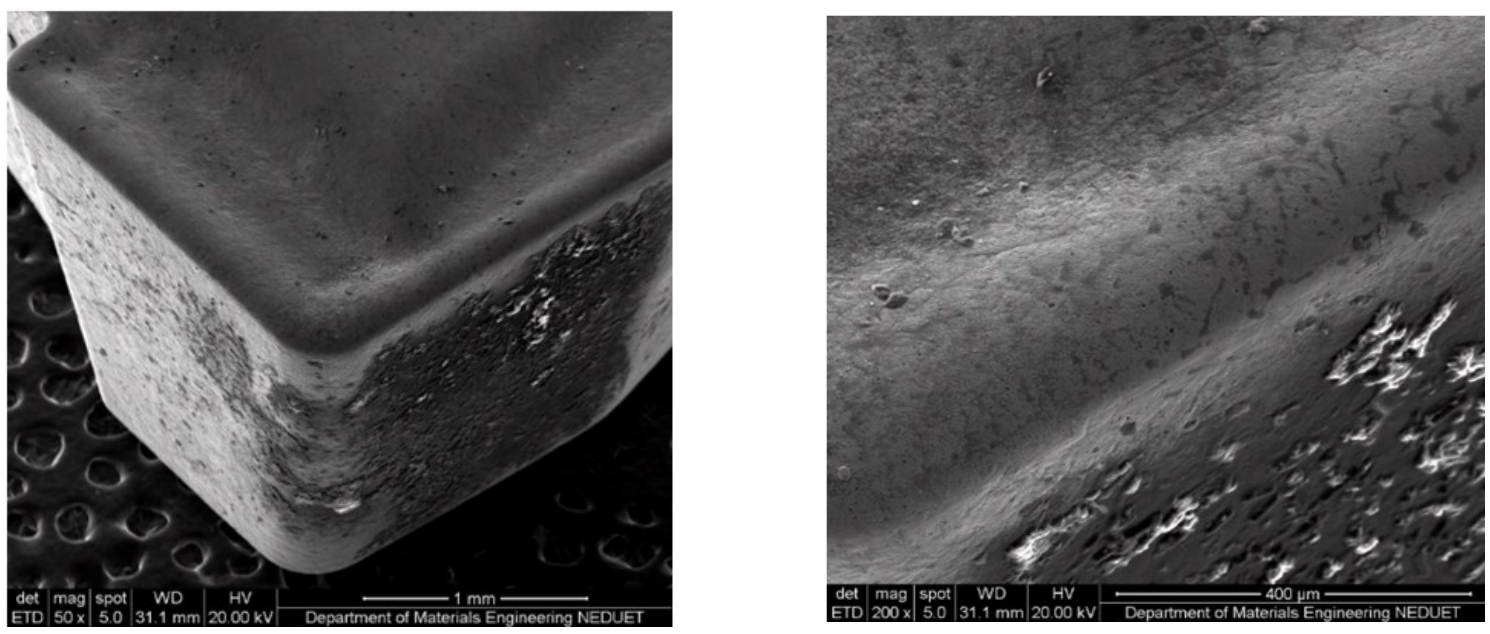

FIG. 9. SEM IMAGES OF DRILLING INSERTS AFTER THE MACHINING OF CFRP AT 1500RPM

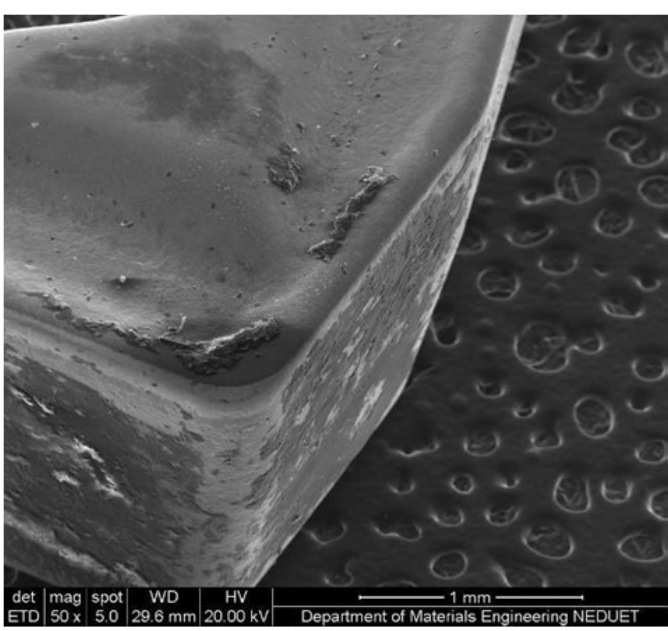

FIG. 10. SEM IMAGES OF DRILLING INSERTS AFTER THE MACHINING OF CFRP AT 2000RPM

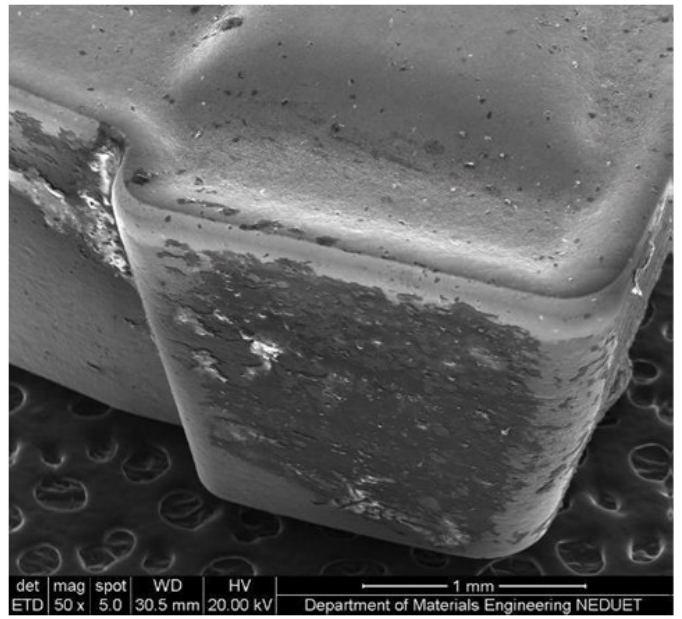

FIG. 11. SEM IMAGES OF DRILLING INSERTS AFTER THE MACHINING OF CFRP AT 2500RPM

Mehran University Research Journal of Engineering \& Technology, Volume 38, No. 3, July, 2019 [p-ISSN: 0254-7821, e-ISSN: 2413-7219] 


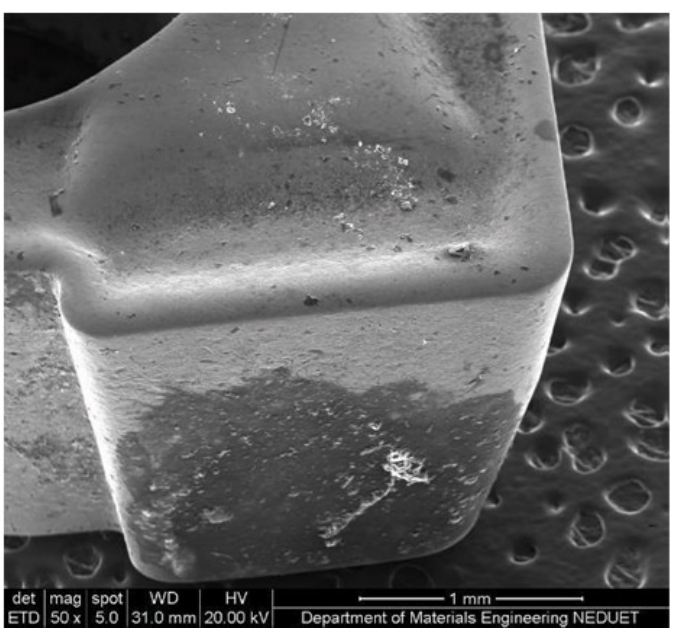

FIG. 12. SEM IMAGES OF DRILLING INSERTS AFTER THE MACHINING OF KFRP AT 1500RPM

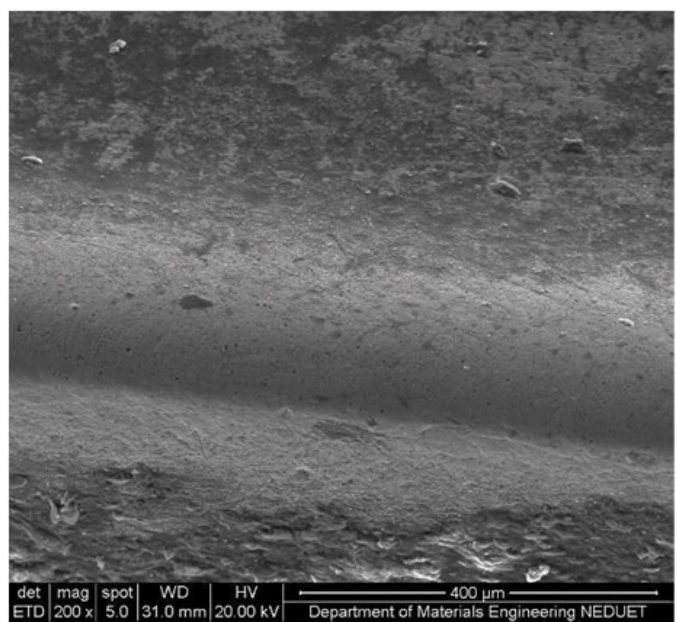

FIG. 13. SEM IMAGES OF DRILLING INSERTS AFTER THE MACHINING OF KFRP AT 2000RPM

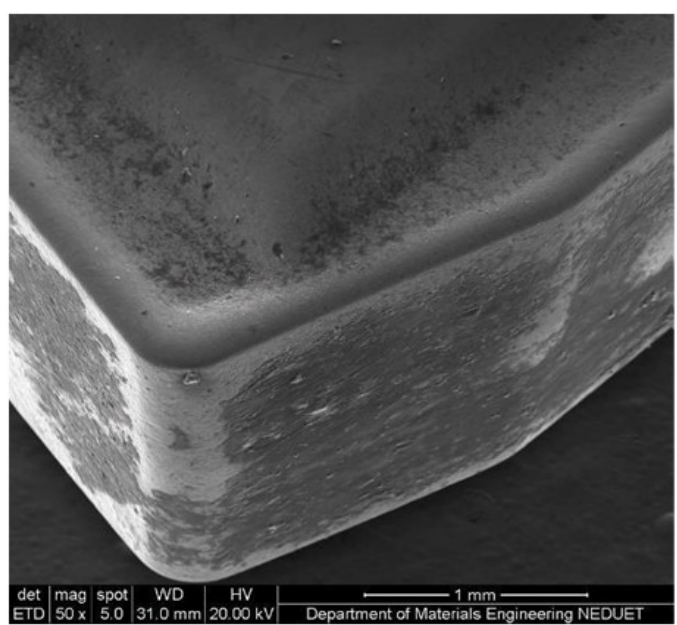

FIG. 14. SEM IMAGES OF DRILLING INSERTS AFTER THE MACHINING OF KFRP AT 2500RPM

\section{CONCLUSION}

The objective of this study is to evaluate the effects of machining parameters of drilling, with the same tool and cutting parameters on three composite materials (GFRP, CFRP and KFRP) and then selection of optimal values for drilling achieving better surface finish. Samples of $8 \mathrm{~mm}$ thickness are machined (drilled) using $13.5 \mathrm{~mm}$ diameter PVD coated carbide indexable type drill bit (made: KYOCERA). Effect of spindle speed (RPM) on surface roughness of the drilled work piece is analyzed. Keeping constant feed of $0.2 \mathrm{~mm} / \mathrm{rev}$, three sets of spindle speeds i.e. 1500, 2000 and 2500 RPM are selected for drilling each of the three materials. Surface roughness values are observed,

In drilling GFRP samples, at lower spindle speed of the three values, i.e. at 1500 RPM, better surface finish is achieved in drilling CFRP samples, as spindle speed is 2000 RPM (between lower and higher value), surface roughness value decreases and better surface is achieved. In drilling KFRP samples, for optimum surface roughness value, at 2500 RPM (highest spindle speed) greater surface finish is achieved

It can also be concluded that the tool wear on the PVD coated cemented carbide is least while drilling of all three types of composite, whereas, depletion of the PVD coating increases with the increase in the cutting speed, which may lead to the built-up edges or sticking of composite material on the drill inserts.

\section{ACKNOWLEDGEMENT}

Authors are thankful to Dr. Ali Dad Chandio, Department of Materials Engineering, NED University of Engineering \& Technology, Karachi, Pakistan, and his team for the preparation of work piece samples in the Department of Materials Engineering. Authors are also thankful to Mr. Muhammad Ali, Department of Industrial \& Manufacturing, NED University of Engineering and Technology, in the for providing his services in measurement of surface roughness and other results.

Mehran University Research Journal of Engineering \& Technology, Volume 38, No. 3, July, 2019 [p-ISSN: 0254-7821, e-ISSN: 2413-7219] 


\section{REFERENCES}

[1] Hoa, S.V., "Principles of the Manufacturing of Composite Materials", DEStech Publications Inc., Lancaster, PA, 2009.

[2] Windhorst, T., and Blot, G., "Carbon-Carbon Composites: A Summary of Recent Developments and Applications", Materials \& Design, Volume 18, No. 1, pp. 11-15, 1997.

[3] El-Sonbaty, I., Khashaba, U.A., and Machaly, T., "Factors Affecting the Machinability of GFR/Epoxy Composites", Composite Structures, Volume 63, No. 3-4, pp. 329-338, [DOI: 10.1016/j.compstruct. 2011.11.024], 2004.

[4] Liu, D.F., Tang, Y.J., and Cong, W.L., "A Review of Mechanical Drilling for Composite Laminates", Composite Structures, Volume 94, No. 4, pp. 1265-1279, 2012.

[5] Dandekar, C.R., and Shin, Y.C., "Modeling of Machining of Composite Materials: A Review", International Journal of Machine Tools and Manufacture, Volume 57, pp. 102-121, [DOI: 10.1016/j.ijmachtools.2012.01.006.], 2012.

[6] Wang, X.M., and Zhang, L.C., "An Experimental Investigation into the Orthogonal Cutting of Unidirectional Fibre Reinforced Plastics", International Journal of Machine Tools and Manufacture, Volume 43, pp. 1015-1022, 2003.

Zhang, H., Chen, W., Chen, D., and Zhang, L.C., "Assessment of the Exit Defects in Carbon FibreReinforced Plastic Plates Caused by Drilling”, Key Engineering Materials, Volume 196, pp. 43-52, 2001.

[8] Inoue, H., Amoyama, E., Hirogaki, T., Ogawa, K., Matushita, H., Kitahara, Y., and Katayama, T., "Influence of Tool Wear on Internal Damage in Small Diameter Drilling in GFRP", Composite Structures, Volume 39, No. 1-2, pp. 55-62. [DOI: 10.1016/S0263-8223(97) 00068-8], 1997.

[9] Javier, T.J., "Analysis of Tool Wear After Machining of Fibre Reinforced Polymers", Thesis, Universidad Carlos III de Madrid, Spain, 2012.

[10] Tsao, CC., and Hocheng, H., "The Effect of Chisel Length and Associated Pilot Hole on Delamination when Drilling Composite Materials", International Journal of Machine Tools and Manufacture, Volume 43, pp. 1087-1092, 2003.
[11] Davim, J.P., Reis, P., and Antonio, C.C., "Experimental Study of Drilling Glass Fibre Reinforced Plastics (GFRP) Manufactured by Hand Lay-Up", Composites Science and Technology, Volume 64, No. 2, pp. 289-297, 2004.

[12] Abrao, A.M., Faria, P.E., Campos, Rubio, J.C., Rels, P., and Damn, J.P., "Drilling of Fiber Reinforced Plastics: A Review", Journal of Materials Processing Technology, Volume 186, pp. 1-7, 2007.

[13] Shyha, I.S., Soo, S.L., Aspinwall, D.K., Bradley, S., Perry, R., Harden, P., and Dawson, S., "Hole Quality Assessment Following Drilling of Metallic-Composite Stacks", International Journal of Machine Tools and Manufacture, Volume 51, No. 7-8, pp. 569-578, 2011.

[14] Zitoune, R.V., Krishnaraj, V., and Collombet, F., "Study of Drilling of Composite Material and Aluminum Stack", Composite Structures, Volume 92, No. 5, pp. 1246-1255, 2010 .

[15] Zitoune, R.V., Krishnaraj, V., Collombet, F., and Le, R.S., "Experimental and Numerical Analysis on Drilling of Carbon Fibre Reinforced Plastic and Aluminum Stacks", Composite Structures, Volume 146, pp. 148-158, 2016.

[16] Jinyang, X., and Mansori, M.E., "Experimental Study on Drilling Mechanisms and Strategies of Hybrid CFRP/ Ti Stacks", Composite Structures, Volume 157, pp. 461-482, 2016,

[17] Jinyang, X., Mkaddemab, A., and Mansori, M.E., "Recent Advances in Drilling Hybrid FRP/Ti Composite: A Stateof-the-Art Review", Composite Structures, Volume 135, pp. 316-338, 2016.

[18] Xing, W., Kwona, P.Y., Sturtevant, C., Kimb, D.W., and Lantrip, J, "Comparative Tool Wear Study Based on Drilling Experiments on CFRp/Ti Stack and its Individual Layers", Wear, Volume 317, No. 1-2, pp. 265-276, 2014.

[19] Rahme, P., Landon, Y., and Lachaud, F., "Drilling of Thick Composite Materials Using a Step Gundrill”, Composites Part-A: Applied Science and Manufacturing, Volume 103, pp. 304-317, 2017.

[20] Ramesh, B., Elayaperumal, A., Satishkumar, S., and Kumar, A., "Drilling of Pultruded and Liquid Composite Moulded Glass/Epoxy Thick Composites: Experimental and Statistical Investigation", Measurement, Volume 114, pp. 109-121, 2017.

[21] Kyocera, "Cutting Tools Drilling Catalog", Kyocera Cutting Tool Division, Wapakoneta, OH, 2013. 